This is a preprint of an article whose final and definitive form will be

published in the Australasian Journal of Philosophy; the Australasian

Journal of Philosophy is available online at:

http://www.tandf.co.uk/journals/.

\title{
AGAINST THE COMPOSITIONAL VIEW OF FACTS
}

\author{
William Bynoe
}

It is commonly assumed that facts would be complex entities made out of particulars and universals. This thesis, which I call Compositionalism, holds that parthood may be construed broadly enough so that the relation that holds between a fact and the entities it 'ties' together counts as a kind of parthood. I argue firstly that Compositionalism is incompatible with the possibility of certain kinds of fact and universal, and, secondly, that such facts and universals are possible. I conclude that Compositionalism is false. What all these kinds of fact and universal have in common is a violation of supplementation principles governing any relation that may be intelligibly regarded as a kind of parthood. Although my arguments apply to Compositionalism generally, I focus on recent work by David Armstrong, who is a prominent and explicit Compositionalist.

\section{Introduction}

Facts provide one account of the instantiation of universals. For a fact theorist, a's instantiating $F$ or a's bearing $R$ to $b$ is accounted for in terms of the existence of the fact that $\mathrm{a}$ is $\mathrm{F}$ and the fact that a bears $\mathrm{R}$ to $\mathrm{b}$ respectively. Among those who believe that there are such entities as facts, it is common to suppose that they are constructed out of the entities they 'tie' together; that they are complex entities made out of particulars and universals. For example, 
David Armstrong says of the fact that a has $\mathrm{R}$ to $\mathrm{b}$ that it has $\mathrm{a}, \mathrm{R}$ and $\mathrm{b}$ as 'parts'; that this fact is 'composed' of them 'in some clear sense of the word 'composed"' [1986: 85]. ${ }^{1}$ According to this outlook, parthood may be construed broadly enough so that the relation that holds between a fact and the entities it 'ties' together counts as a kind of parthood.2 Let's call this thesis Compositionalism. Here I will argue that Compositionalism is incompatible with the existence of certain kinds of fact and universal. For example, Compositionalism is incompatible with there being a universal such that it's a fact that it instantiates itself. There are other, more complicated cases. What they all have in common is a violation of principles that the Compositionalist must endorse if their view is to have any content. We must either reject Compositionalism or deny that there are, or could be, ${ }^{3}$ such facts and universals. Having established that we are faced with this dilemma, I will urge that we reject Compositionalism. It is highly plausible that the problematic kinds of fact and universal are at least possible. Compositionalism's incompatibility with them shows that it cannot accommodate legitimate phenomena. A different theory of instantiation is therefore required.

The many fact theorists do not entirely agree about the nature of facts, so it is difficult to discuss the Compositional view in the abstract. My argument applies to any such view, but it will help to focus on a particular philosopher. I will focus on Armstrong, since he is a prominent and explicit Compositionalist.

\footnotetext{
${ }^{1}$ Similar claims can also be found in Moore [1953: 303], Russell [1956], Taylor [1985] and Mellor [1995]. It is arguable that Wittgenstein's Tractatus should be on this list too, though there are various relevant interpretive issues [e.g. see Simons 1992: 319-38].

${ }^{2}$ I will assume that nothing is part of itself: the relation I am talking about is what philosophers often call 'proper parthood'.

${ }^{3}$ The (mere) possibility of the problem cases is incompatible with Compositionalism if the latter is assumed to be necessarily true if true. I will assume this to be the case.
} 


\section{The argument}

My objection may be regarded as extending a debate conducted in the Australasian J ournal of Philosophy in 1986. There, David Lewis gave several arguments against structural universals. In the discussion that followed his paper, it was agreed between Lewis and his opponents (Armstrong among them) that what was centrally at issue was the extensionality of composition: the principle that two complex entities can't have all the same parts [Armstrong 1986; Forrest 1986; Lewis 1986]. Armstrong argued that the theory of universals ought to reject this principle not only because it's violated by structural universals, but also because it's violated by facts [1986: 85]. For example, the fact that Romeo loves J uliet is distinct from the fact that J uliet loves Romeo, but they are made of the same entities. Lewis replied that this was a good reason to reject facts. His argument was that all composition must be understood in terms of extensional mereology. It is part of that theory that composition is extensional. Therefore, the relation that would hold between a fact and its parts could not be the relation described by extensional mereology. No other kind of parthood is intelligible, so there cannot be any facts [1986: 92. See also: 1991: 57; 1992: 213].

Armstrong's response has been to insist on a broader notion of parthood, one that includes two species. He grants that extensional mereology describes one species of parthood. The sort of composition it gives rise to is extensional, in the above sense. He calls this species of parthood and composition 'mereological'. In addition to this species of parthood, Armstrong posits the kind that holds between a fact and the entities that make it up. The sort of 
composition it gives rise to is not extensional. Oxymoronically, he calls this species of parthood and composition 'non-mereological' [2004: 18, 71]. Often, to mark this distinction, Armstrong uses 'part' for mereological parts and 'constituent' for the parts of facts [1997: 119-23; 2004: 18]. He is explicitly a mereological dualist; he thinks that extensional mereological parthood and constituenthood are the two kinds of parthood [2004: 18, 71].

Let's grant that it's intelligible to divide parthood into two species; to suppose that there are two 'forms of composition' [ibid: 18]. On this view, there are principles that govern some but not all kinds of parthood/composition. For example, Armstrong posits both an extensional and a non-extensional form of composition: respectively, the form of composition described by extensional mereology and the form of composition that yields facts. Nevertheless, it is surely true that there are some principles that govern all kinds of parthood/ composition. For example, if some relation, R, is a kind of parthood, then it must be asymmetric. ${ }^{4}$ No sense can be made of the supposition that $y$ is among the things that collectively make up $\mathrm{x}$, and also that $\mathrm{x}$ is among the things that make up y. No relation that isn't asymmetric could intelligibly be regarded as a kind of parthood.

As Peter Simons has made plain, also fundamental to any sort of parthood is that no complex entity can have a single part [1987: 26]. Anything with parts, in any sense of parthood, must have at least two. ${ }^{5}$ Call any principle that specifies how a part must be supplemented to produce a complex whole, a

\footnotetext{
${ }^{4}$ Recall that I'm discussing proper parthood.

${ }^{5}$ I know of only one philosopher who disagrees [see Fine 2007]. I will assume the orthodox view that Simons is right here.
} 
supplementation principle. The weakest is:

Non-identity Supplementation: For all kinds of parthood, if $\mathrm{y}$ is a part of $\mathrm{x}$ then there's something non-identical with y that is a part of $\mathrm{x}$ [ibid: 26].

If this is denied, one loses one's grasp on what it means for a complex entity to be made out of other entities, i.e. its parts. It makes no sense to say that a thing has a part, but has only one. ${ }^{6}$ The Compositionalist must therefore suppose that the relation that holds between a fact and the entities it 'ties' together obeys Non-identity Supplementation. If this is denied, Compositionalism ceases to have any content.

Now, Armstrong maintains that a kind of parthood holds between a fact and each of the entities it 'ties' together. By Non-identity Supplementation, it follows that if $\mathrm{y}$ is a part of some fact, $\mathrm{x}$, then $\mathrm{x}$ has a part that is not identical to y. This rules out the possibility of universals that instantiate themselves. Consider a universal, $\mathrm{F}$, that instantiates itself. If there is such a universal, the Compositionalist will posit the fact that is the 'tying' of $F$ to itself. This fact that F is F would have only one part: F. By Non-identity Supplementation, there can be no such fact. So the Compositionalist must deny that F exists. Therefore, Compositionalism is incompatible with the possibility of selfinstantiating universals.

We must reject either Compositionalism or the possibility of self-instantiation.

\footnotetext{
${ }^{6}$ It would be a mistake, I think, to object here that there is a kind of parthood that $\varnothing$ and nothing else bears to $\{\varnothing\}$. Such a claim would presumably be motivated by regarding sets as complex entities constructed out of their members. However, there are good reasons to regard this conception of sets as mistaken [see e.g. Oliver 1993; Parsons 1995]. Here, I will simply assume that this conception is false.
} 
The former option is to be preferred. Self-instantiation is intelligible and unobjectionable. This is strong evidence for its possibility. That selfinstantiating universals are intelligible is shown by the existence of prima facie examples: being multiply located, being instantiated, being a property. ${ }^{7}$ (Armstrong himself has posited the last universal on this list in order to allow for laws with universal scope [1978: 145; 1983: 141-2].) Of course, a Compositionalist may deny that these three universals exist. But the ease with which we can we can produce candidate self-instantiating universals strongly suggests that such entities are intelligible. This is good evidence that selfinstantiation is possible. So Compositionalism cannot accommodate a genuine possibility. Furthermore, there is nothing self-defeating about selfinstantiation. The nature of self-instantiating universals does not defeat the point of positing them. Armstrong persuasively argues against disjunctive and negative universals on the grounds that they would not fulfil the roles characteristic of universals. In particular, the sharing of them would not make for similarity [e.g. 1978: 20, 23-4]. However, the same cannot be said of selfinstantiating universals. A self-instantiating universal could be a respect of resemblance. For example, sharing of the above prima facie self-instantiating universals does make for similarity. A Compositionalist might contend that self-instantiating universals are ruled out by the nature of the facts in which they would be required to feature. The idea is that since facts are as the Compositionalist conceives them, self-instantiation must be impossible. But this is a weak position. Other than its incompatibility with Compositionalism, we have no reason to repudiate the possibility of self-instantiation. Moreover, other theories of instantiation, such as those that avoid facts, are compatible

\footnotetext{
${ }^{7}$ And, extending our argument to relations, there's identity, which relates itself to itself.
} 
with self-instantiation. Its incompatibility with self-instantiation just shows that Compositionalism cannot accommodate a legitimate phenomenon. So, Armstrong is wrong to suppose that a kind of parthood holds between a fact and each of the entities it 'ties' together. Compositionalism is a mistake.

Non-identity Supplementation, though true, is not strong enough to specify how a part must be supplemented to produce a complex whole. To see that it's too weak, consider that it allows $\mathrm{x}$ to be formed by supplementing $\mathrm{y}$ with a part of y [Simons 1987: 27]. (In turn, y may be formed by supplementing this part of $y, z$, with a part of $z$. And so on.) It is clear that a supplementation principle at least this strong is therefore needed:

Non-parthood Supplementation: For all kinds of parthood, if $\mathrm{y}$ is a part of $\mathrm{x}$ then there's something, $z$, such that (1) z is a part of $x,(2) z$ isn't a part of $y,(3)$ zisn't y [ibid.]. ${ }^{8}$

If Compositionalism is to have content, it must involve the claim that the relation that holds between a fact and the entities it 'ties' together obeys Nonparthood Supplementation.

As before, this principle, together with Compositionalism, rules out the existence of certain kinds of fact and universal. Consider an object, a, that has a property, F. So there's the fact that a has F. Call it y. Suppose that this fact, y, itself has the property F. So there's a further fact, the fact that y has F. Call it x.

\footnotetext{
${ }^{8}$ It is plausible that an even stronger supplementation principle is needed [Simons: 28]. I will make no use of this fact.
} 
Given Armstrong's view, if this scenario were possible, then y would be a part of $\mathrm{x}$. However, $\mathrm{x}$ would have no other parts that aren't themselves part of $\mathrm{y} . \mathrm{x}$ 's other part would be F, which is a part of y. ${ }^{9}$ By Non-parthood Supplementation, there can be no such complex entity. If, in some sense of part, facts 'tie' together their parts, then Non-parthood Supplementation tells us that $\mathrm{x}$ cannot exist. Therefore, Compositionalism is incompatible with the possibility of such facts.

We must reject either Compositionalism or the possibility of the above kind of fact. Again, rejecting Compositionalism is preferable. It is perfectly intelligible for there to be a universal that is had by both facts and particulars. And it is equally intelligible for such a universal to be had by the fact that some particular has it. Prima facie examples are provided by: existence, being located, being a particular. So, for example, each fact is a particular rather than a universal [e.g. Armstrong 1997: 126]. Therefore, if there is the universal of being a particular, then there's the fact that Socrates is a particular, and the fact that this fact is a particular. The latter fact is of the problematic form described above. Of course, a Compositionalist might deny that there's the universal of being a particular (and also reject existence and being located). But, again, the ease with which we can produce candidate universals that would realise our problem case strongly suggests that such entities are intelligible. This is good evidence that they are possible. So Compositionalism cannot accommodate a genuine possibility. Furthermore, exactly the same points can be made in favour of this conclusion as were made above in favour

\footnotetext{
${ }^{9}$ A complication here is that if parthood is transitive, $a$ is also a constituent of x. Like F, $a$ is a part of the fact that $a$ is $\mathrm{F}$.
} 
of the conclusion that self-instantiation is possible. In particular: positing the problematic universals is not self-defeating, and is compatible with other theories of instantiation. So, the fact that Compositionalism is incompatible with our problem case just shows that it cannot accommodate a legitimate phenomenon. 10

To sum up: kinds of parthood must be governed by Non-identity and Nonparthood Supplementation. If one follows Armstrong in supposing that facts are complex items made out of the entities they 'tie', we've seen that it follows that certain kinds of fact and universal cannot exist. So, Compositionalism is incompatible with the existence of such facts and universals. Furthermore, it is possible for such facts and universals to exist. That Compositionalism is incompatible with the existence of such entities shows that it cannot accommodate legitimate phenomena. So Compositionalism is false; facts are not complex items made out of the entities they 'tie'.

\section{Objections}

Let's assume that the discussed problematic facts and universals are indeed possible. Given this, there are two ways the Compositionalist could respond to the above. First, they could maintain that Compositionalism is compatible with the fact that constituenthood violates supplementation principles. Second, they could amend Compositionalism so that those principles are not violated. Neither strategy will work. I will consider the first in 3.1, and the second in 3.2.

\footnotetext{
${ }^{10}$ There are other facts ruled out by Compositionalism and Non-parthood Supplementation. For example: neither $a, b$, nor the fact that $a$ bears $\mathrm{R}$ to $b$ can bear $R$ to the fact that $a$ bears $R$ to $b$. The same conclusions should be reached here as above.
} 


\subsection{Compositionalism without Supplementation Principles}

Could Armstrong respond in the same sort of way in which he responded to Lewis? Could he say that just as constituenthood gives rise to a form of composition that is not extensional, it is also a kind of parthood that is not governed by supplementation principles? Could he insist on a really broad notion of parthood, where one species of it can give rise to complex entities which have unsupplemented parts? No. Contra Lewis, one can posit a kind of composition that is not extensional without thereby losing one's grasp on the notions of composition and parthood. Indeed, many mereologists argue against extensional mereology and the extensionality of composition [e.g. van Inwagen 1990; J ohnston 2006]. To suppose that all forms of composition have this feature is highly controversial. In contrast, only the most eccentric mereologist would suppose that there's a kind of parthood that violates the weakest supplementation principles. If a relation is not governed by supplementation principles, it is no longer intelligible to regard it as a kind of parthood. To suppose otherwise would be akin to supposing that resemblance is a non-transitive kind of identity. Such a claim manifests a misunderstanding of that relation. Similarly, the Compositionalist who denies that constituenthood obeys Non-identity and Non-parthood Supplementation would betray a serious misunderstanding of the nature of parthood.

Consider an alternative, subtly different, response on behalf of Armstrong. The thesis that constituenthood is a kind of parthood should be abandoned, since that relation doesn't obey supplementation principles. Nonetheless, facts are 
composed out of their constituents. This form of composition is non-

mereological; it is not understood in terms of any kind of parthood. ${ }^{11}$ Thus we can respond to the problem posed while maintaining Compositionalism.

This response fails to appreciate a fundamental truth regarding complex entities: supplementation principles govern the relation that holds between a complex entity and the things that make it up. So, if constituenthood is not governed by supplementation principles, facts are not complex items made out of the entities they 'tie' together. To suppose otherwise is to betray a serious misunderstanding of the nature of complexity. Of course, it is legitimate to use constituenthood, a non-mereological relation, to define a many-one relation that holds between a fact and the entities it 'ties'. The defined many-one relation will also be non-mereological. One may call this many-one relation 'composition', and talk of a 'non-mereological form of composition', but this would be misleading. It would suggest that facts are complexes made out of other entities when, in fact, they are not.

\subsection{Amending Compositionalism}

An alternative line of response is to amend Compositionalism in such a way that, even though constituenthood is governed by supplementation principles, the problematic facts and universals are accommodated. I know of only one way to try to do this. ${ }^{12}$ In this section, I will argue that it does not work.

\footnotetext{
${ }^{11}$ By 'non-mereological form of composition' I do not here mean what Armstrong means. The idea isn't that there's a kind of composition different from that described by extensional mereology. The idea is that there's a kind of composition that isn't understood in terms of any kind of parthood.

${ }^{12}$ The line of response discussed in this section was proposed by an anonymous referee.
} 
As conceived of so far, the Compositionalist supposes that facts are made out of only the entities they 'tie'. ${ }^{13}$ This is Armstrong's view. Consider again the fact that J uliet loves Romeo (call it $\mathrm{x}$ ) and the fact that Romeo loves J uliet (call it $y$ ). Armstrong maintains that $x$ and $y$ have the same parts: $J$ uliet, loving and Romeo. As explained, this is one reason why he thinks that constituenthood cannot be the same species of parthood as that described by extensional mereology. Now, it is the thesis that facts are made out of only the entities they 'tie' that causes trouble for Compositionalism. From this thesis it follows that the fact that F is F would have only one part: F. Since constituenthood is governed by Non-identity Supplementation, it follows that Compositionalism cannot accommodate such cases of self-instantiation. If we could motivate adding more parts to facts, perhaps we could supplement the problematic facts discussed above. So, for example, the fact that $\mathrm{F}$ is $\mathrm{F}$ would have some other part, besides F. Thus Non-identity Supplementation would be obeyed and so Compositionalism would accommodate self-instantiation.

I know of only one way to pursue this strategy. First, we must realise that order plays a key role in the making up of facts. $\mathrm{x}$ and $\mathrm{y}$ 'tie' the same entities, but order them differently. Somehow, the fact theorist must account for this difference. One option is to suppose that each fact has as a part an entity which is the order in which its other parts are 'tied'. $\mathrm{x}$ and $\mathrm{y}$ order J uliet, Romeo and loving differently. So the entity which is the order in which J uliet et al are 'tied' by $\mathrm{x}$ is distinct from the entity which is the order in which these same entities are 'tied' by y. These entities, call them order-constituents, are extra parts of $\mathrm{x}$ and $\mathrm{y}$ respectively. Therefore, contra Armstrong, $\mathrm{x}$ and $\mathrm{y}$ do not have all the same parts. Crucially, for our discussion, the problematic facts will be similarly supplemented, and, perhaps, there won't be any violation of supplementation principles.

To pursue this strategy, we need to know more about these new entities. An order-constituent is a particular order in which some particular things may

\footnotetext{
${ }^{13}$ As well as any parts of any facts they 'tie', if parthood is transitive (see footnote 9).
} 
occur in a fact. So it seems each must be an ordering of the things in question. One idea is that x's order-constituent is a sui generis entity which is J uliet, loving, and Romeo in some particular order. It is in virtue of them being in that order in that order-constituent that the latter imposes a particular order upon x's other parts. Note that if these order-constituents are to supplement the problematic facts, they must be distinct from each of the entities they impose order upon. Nonetheless, they must 'involve' those entities; there must be some reason why x's order-constituent is J uliet, loving and Romeo in some order, rather than some other things in some other order. Now a problem becomes clear. On this view, the structure of a fact is supposed to be accounted for in terms of the structure of its order-constituent. But what accounts for the latter? How does an order-constituent 'involve' some entities in a particular order? If the structure of order-constituents, so conceived, is accounted for without supposing that each 'involves' an entity that imposes order on the other entities it 'involves', then this undermines the introduction of order-constituents. The same technique should explain the structure of facts, and order-constituents would be surplus to requirements. On the other hand, suppose the structure of order-constituents is accounted for in terms of the 'involvement' of further order-'constituents'. This chain either terminates with some novel account of order, thus making order-constituents redundant, or it is infinite, in which case we have a vicious regress.

The moral is that we must analyse the order of order-constituents. The only known reductions of order are the familiar set-theoretic ones. So, consider construing order-constituents as ordered sequences, and analysing them in terms of unordered collections. For example, we could take x's orderconstituent to be the ordered set: $\langle\mathrm{J}$ uliet, loving, Romeo $>$. We then analyse such ordered sets in terms of unordered sets. ${ }^{14}$ For example, x's orderconstituent might really be:

\footnotetext{
${ }^{14}$ This strategy is closely related to one employed by Bergmann [1981]. He uses diads, a new kind of entity he introduces, rather than sets. But, as Hochberg points out, Bergmann's diads are merely sets renamed [1981: 233].
} 
$\{$ J uliet\}, J uliet, \{\{loving\}, \{loving, Romeo $\}\}\}\} .15$

By analysing order in this way, we avoid the above objection. The above set is unordered, so there is no need to account for how an order-constituent 'involves' some entities in a particular order. However, the problem with this approach is familiar. There are an infinite number of equally legitimate procedures for 'reducing' ordered sets to unordered ones. It is plainly misguided to choose between them. But if none is chosen, the desired reduction is not carried out. ${ }^{16}$

Let's take stock. Recall that the original idea was to account for the difference between $\mathrm{x}$ and $\mathrm{y}$ by supplementing facts with an entity which is the order in which their other parts are 'tied'. It seems the only candidate is orderings of the parts in question. We can either regard these entities as structured, or try to analyse their structure. Neither option is tenable. It is therefore doubtful whether this whole strategy can succeed. Furthermore, it seems to me that this strategy is wrongheaded. It is common for the parts of a complex to be structured in a particular way. (Consider houses, weddings, films, etc.). But it seems mistaken to suppose that the structure of a complex is a further part of it. There is a way in which a complex's parts are arranged, but this way is not among the entities that go together to make up the complex. ${ }^{17}$

I know of no other good reason to amend Compositionalism by supplementing complex facts with additional parts. Plausibly, if facts are complex, we must conceive of them as Armstrong has: their only parts are the entities they 'tie'. As we've seen, though, this thesis should be rejected.

\section{A Suggestive Conclusion}

\footnotetext{
${ }^{15}$ Here I'm using the Wiener-Kuratowski procedure.

${ }^{16}$ Cf. Benacerraf 1965. For further elaboration see Hochberg [1981: 232-3] and MacBride [2005: 591].

${ }^{17}$ See e.g. Johnston [2006: 659].
} 
Given that unamended Compositionalism is the only way to construe facts as complex, either there are no facts or they are simple. It might seem that they cannot be simple, so there cannot be facts. However, it might be possible to advocate facts without conceiving of them as complex. The fact theorist ought to consider a Structuralist alternative. Consider the fact that Socrates is wise, call it $\mathrm{x}$. For the Compositionalist, $\mathrm{x}$ is the fact that it is in virtue of being a complex entity made out of Socrates and wisdom. It gets its identity from its internal complexity. In contrast, the Structuralist supposes that x itself has no internal complexity, so cannot get its identity from the way it is constructed out of other entities. Rather, it derives its identity from non-mereological18 ways of being related to other entities, such as Socrates and wisdom. ${ }^{19}$ Compare this approach to the Structuralist view of sets [e.g. Parsons 1995]. It is common to talk as if sets are complex entities made out of their members. This suggests a Compositional view of them. ${ }^{20}$ An alternative is a Structural view according to which sets have no internal complexity, and get their identity from the non-mereological ways they are related to other objects, i.e. their members. Since the Compositional view of facts is false, it would be worth exploring the option of conceiving of facts in an analogous way. ${ }^{21}$

\section{Institute of Philosophy, School of Advanced Study, University of London}

\footnotetext{
${ }^{18}$ By 'non-mereological' I mean 'not pertaining to parthood'. I do not mean 'not pertaining to extensional mereology'.

${ }^{19}$ For example, Keith Hossack has recently advocated a Structuralist view of facts on which $\mathrm{x}$ is simple but 'combines' Socrates and wisdom, where combination is a sui generis, non-mereological relation [2007: 45-6]. I have shown that fact theorists ought to reject Compositionalism in favour of this sort of view. Notice that the second response in section 3.1 above effectively gestures towards a view like Hossack's. Combination is the non-mereological many-one relation that was, in that response, misleadingly called 'composition'.

${ }^{20}$ As stated in footnote 6 , I think this is a mistaken view.

${ }^{21}$ I am very grateful to Fraser MacBride for advice and discussion. Thanks also to Nick Jones, Chris Machut, Mark Textor, Lee Walters and three helpful anonymous referees. I would like to acknowledge the support of the Jacobsen Trust and the Institute of Philosophy, where I am currently a Jacobsen Fellow.
} 
University College London

\section{References}

Armstrong, David 1978. A Theory of Universals, Cambridge: Cambridge University Press.

Armstrong, David 1983. What is a Law of Nature, Cambridge: Cambridge University Press.

Armstrong, David 1986. In Defence of Structural Universals, Australasian J ournal of Philosophy 64/ 1: 85-8.

Armstrong, David 1997. A World of States of Affairs, Cambridge: Cambridge University Press.

Armstrong, David 2004. Truth and Truthmakers, Cambridge: Cambridge University Press.

Benacerraf, Paul 1965. What Numbers Could Not Be, Philosophical Review 74/ 1: 47-73.

Bergmann, Gustav 1981. Notes on Ontology, Nous 15/ 2: 131-54.

Fine, Kit 2007. Response to Kathrin Koslicki, Dialectica 61/ 1: 161-6.

Forrest, Peter 1986. Neither Magic nor Mereology: A Reply to Lewis, Australasian J ournal of Philosophy 64/ 1: 89-91.

Hochberg, Herbert 1981. Logical Form, Existence, and Relational Predication, in Midwest Studies in Philosophy 6, ed. Peter A. French, Theodore E. Uehling, and Howard Wettstein, Minneapolis: University of Minnesota Press: 215-38.

Hossack, Keith 2007. The Metaphysics of Knowledge, Oxford: Oxford University Press. 
J ohnston, Mark 2006. Hylomorphism, The J ournal of Philosophy 103/ 12: 652-98.

Lewis, David 1986. Comment on Armstrong and Forrest, Australasian J ournal of Philosophy 64/ 1: 92-93.

Lewis, David 1991. Parts of Classes, Oxford: Basil Blackwell.

Lewis, David 1992. Critical Notice of Armstrong, D.M., A Combinatorial Theory of Possibility, Australasian J ournal of Philosophy 70/2: 211-24. MacBride, Fraser 2005. The Particular-Universal Distinction: A Dogma of Metaphysics?, Mind 114/ 4: 565-614.

Mellor, D. H. 1995. The Facts of Causation, London: Routledge.

Moore, G. E. 1953 (1910). Some Main Problems of Philosophy, London: Allen and Unwin.

Oliver, Alex 1993. Classes and Goodman's Nominalism, Proceedings of the Aristotelian Society 93: 179-91.

Parsons, Charles 1995. Structuralism and the Concept of Set, in Modality, Morality and Belief: Essays in Honour of Ruth Barcan Marcus, ed. Walter Sinnott-Armstrong, Dianna Raffman, and Nicholas Asher, Cambridge: Cambridge University Press.

Russell, Bertrand 1956 (1918). The Philosophy of Logical Atomism, in Logic and Knowledge, ed. R.C. Marsh, London: Allen \& Unwin.

Simons, Peter 1987. Parts: A Study in Ontology, Oxford: Clarendon Press.

Simons, Peter 1992. Philosophy and Logic in Central Europe from Bolzano to Tarski, Dordrecht: Kluwer.

Taylor, Barry 1985. Modes of Occurrence: Verbs, Adverbs and Events, Oxford: Blackwell.

van Inwagen, Peter 1990. Material Beings, Ithaca, NY: Cornell University 
Press. 